\title{
GIRONDO O LAS VERSIONES POETICAS DEL CAMBIO
}

\author{
POR \\ OLGA JUZYN-AMESTOY \\ Rhode Island College
}

Una de las constantes en la discusión sobre la modernidad es el cambio. La noción vanguardista del cambio suplanta a la del Modernismo, la cual, sin dejar de ser una escritura de novedad y transición, se limitaba a la asimilación de estilos, escuelas, perspectivas. La poesía del argentino Oliverio Girondo, como obra vanguardista, forma parte de la escritura moderna del cambio, en la que según Fernando Burgos: "Ta transición en lugar de constituir una pura instancia del proceso del cambio es su dinámica, un elemento más y también un agente de una situación en la que el cambio es el único rasgo de permanencia"1. La estasis que resulta no necesariamente refleja una "ausencia de cambio", nos dice Burgos citando a Leonard Meyer; lo que se da, según éste, es la ausencia de "un cambio secuencial ordenado"2. En otras palabras, el cambio deviene importante como proceso más que como resultado.

Este "nuevo" concepto del cambio es también elaborado por el lingüista Eugenio Coseriu, quien busca eludir la estática noción saussuriana de "diacronía" (según la cual el cambio se define como algo externo al sistema, un accidente ya establecido), e insertar el cambio lingüístico en la "sincronía"; es decir, desea formular una descripción del lenguaje a partir de las estrategias del cambio en su desarrollo; es decir, en el habla. Los textos de Girondo demuestran una preocupación con el cambio paralela a la de Coseriu, con quien comparte el deseo de situar el cambio justamente en el hacerse mismo del discurso, y de ahí en su necesidad histórica.

La noción dinámica del cambio desarrollada en la obra de Girondo se da primero dentro de un discurso en prosa (discurso que la vanguardia elige para acercarse al lenguaje de la praxis: al habla en general) y luego en un marco lírico

\footnotetext{
${ }^{1}$ Fernando Burgos, La novela moderna hispanoamericana (un ensayo sobre el concepto literario de modernidad) (Madrid: Orígenes, 1985) 62.

${ }^{2}$ Fernando Burgos, La novela moderna, 90-91. El texto de L. Meyer es "History, Stasis, and Change, the Probability of Stasis, en Music, the Arts and Ideas: Patterns and Predictions in Twentieth-Century Culture. (Chicago \& London: The University of Chicago Press, 1967).
} 
que conserva, empero, calidad oral. El dato nos parece importante porque, según Coseriu, el cambio lingüístico se inicia precisamente en la oralidad ${ }^{3}$.

Elegimos empezar nuestro análisis con el poema "4" del libro Espantapájaros $(1932)^{4}$ porque este poema de por sí anuncia un cambio en la poética de Girondo: por primera vez se da un yo lírico bien identificado, que se dirige en un registro oral al lector. El poema se nos ocurre ejemplar porque su temática y su estructura giran en torno a la oposición "relación/distanciamiento", que creemos esencial en la discusión sobre el cambio. Luego pasaremos a otra instancia: la metamorfosis, en el poema " 16 ", y a textos del siguiente libro de Girondo Persuasión de los días (1942) — para ver en qué dirección se orienta la noción del cambio.

\section{Poema “4”: Estado de cambio}

Abandoné las carambolas por el calambur, los madrigales por los mamboretás, los entreveros por los entretelones, los invertidos por los invertebrados. Dejé la sociabilidad a causa de los sociologos, de los solistas, de los sodomitas, de los solitarios. No quise saber nada con los prostáticos. Preferí el sublimado a lo sublime. Lo edificante a lo edificado. Mi repulsión hacia los parentescos me hizo eludir los padrinazgos, los padrenuestros. Conjuré las conjuraciones más concomitantes con las conjugaciones conyugales. Fui célibe, con el mismo amor propio con que hubiese sido paraguas. A pesar de mis predilecciones, tuve que distanciarme de los contrabandistas y de los contrabajos; pero intimé, en cambio, con la flagelacion, con los flamencos.

Lo irreductible me sedujo un instante. Creí, con una buena fe de voluntario, en la mineralogía y en los minotauros. ¿Por qué razón los mitos no repoblarían la aridez de nuestras circunvoluciones? Durante varios siglos, la felicidad, la fecundidad, la filosofía, la fortuna, ino se hospedaron en una piedra?

¡Mi ineptitud llegó a confundir un coronel con un termómetro!

Renuncié a las sociedades de beneficiencia, a los ejercicios respiratorios, a la franela. Aprendí de memoria el horario de los trenes que no tomaria nunca. Poco a poco me sedujeron el recato y el bacalao. No consentí ninguna concomitancia con la concupiscencia, con la constipación. Fui metodista, malabarista, monogamista. Amé las contradicciones, las contrariedades, los contrasentidos ... y caí en el gatismo, con una violencia de gatillo (OC 1631 64).

${ }^{3}$ Coseriu dice: "El cambio lingǘstico tiene su origen en el diálogo: en el paso de modos lingüísticos del hablar de un interlocutor al saber del otro. Todo aquello en que lo hablado por el hablante -en cuanto modo lingütstico- se aleja de los modelos existentes en la lengua por la que se establece el coloquio, puede llamarse innovación. Y la aceptación de una innovación, por parte del oyente, como modelo para ulteriores expresiones, puede llamarse adopción" (Sincronía, diacronía e historia 78). Con esta distinción Coseriu formula dialécticamente el hacerse de la lengua (y de los hechos culturales en general) y le da cabida al destinatario del enunciado otorgándole responsabilidad en su aceptación de lo emitido.

${ }^{4}$ Utilizamos las Obras Completas de Oliverio Girondo (Buenos Aires: Losada, 1968). Las citas serán en adelante consignadas en el texto. 
El poema anuncia a la vez la consumación y rechazo de un cambio. El yo lírico enjuicia su elección pasada desde la perspectiva del absurdo presente: "Fui célibe con el mismo amor propio con que hubiese sido paraguas"; " $\mathrm{j} \mathrm{Mi}$ ineptitud llegó a confundir un coronel con un termómetro!"; "Aprendí de memoria el horario de los trenes que no tomaría nunca". En el presente de la enunciación, el yo lírico denuncia el cambio - expresado por el uso del pretérito indefinido-, y con ello señala que no se trata de un concepto estático, pues el cambio se extiende hacia el presente y permanece inconcluso. No es fin sino proceso; más que cambio de estado, es estado de cambio. A través de la denuncia, en el ahora de la enunciación poética, la escritura se define como parte de la dinámica del cambio.

El cambio con el que nos enfrentamos se da dentro de una crisis de relación, en un vaivén entre aproximación y distanciamiento. Desde ya la escritura misma de Girondo opera un cambio en lo que atañe a elementos gramaticales; mientras que en Veinte poemas para ser leidos en el tranvía (1922) y Calcomanías (1923), el verbo permanecía en el trasfondo de su discurso, aquí en Espantapájaros (y en adelante) será preponderante. Si nos fijamos en los verbos, que por lo general tienen lugar de privilegio al inicio de la frase, vemos que en ellos se sitúa la tensión del hacerse del cambio:

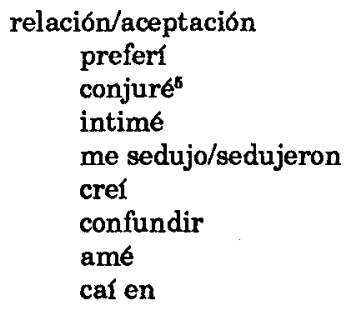

distanciamiento/rechazo
abandoné
dejé
no quise saber nada
eludir
fui (célibe)
tuve que distanciarme
renuncié
no consentí

También reflejan esta tensión los sustantivos y adjetivos: "sociabilidad", "sociólogos", "solistas", "sodomitas", "solitarios", "parentescos", "padrinazgos", "padrenuestros", "conjuraciones", "concomitantes", "conjugaciones", "conyugales", "célibe", "flagelación", "sociedad de beneficiencia", "franela", "concomitancia", "concupiscencia", "monogamista", "contradicciones", "contrariedades", "contrasentidos". El alejarse de las relaciones sociales, sexuales, familiares, se da por "elección" del hablante (abandoné, dejé, mi repulsión, etc.), demostrando con ello que el cambio se da por necesidad del yo, y no como algo impuesto. Y, en la medida en que el yo lírico se lamenta de tales

6 "Conjure" también podría indicar rechazo.

- En lunfardo la franela es una "visita cansadora. En los prostíbulos, el que no gasta y ocupa sitio". El lenguaje de Bajo Fondo (Vocabulario lunfardo) (Buenos Aires: Schapire, 1969) 120. También significa tocarse sexualmente. 
elecciones, sigue ejerciendo su libertad, pues en el presente de la escritura expresa un cambio de actitud. La palabra deviene así proceso continuo de cambio. Proceso y no fin, dado que no se conoce la última voluntad del yo.

El cambio afecta todas las facetas del yo: la social (dejé la sociabilidad), familiar (mi repulsión hacia los parentescos), sexual (fui célibe), la filosófica (... la felicidad, la fecundidad, la filosofia, la fortuna, ¿no se hospedaron en una piedra?), la religiosa (fui metodista), física (intimé ... con la flagelación, renuncié a los ejercicios respiratorios) y también la literaria (abandoné las carambolas por el calambur, los madrigales por los mamboretás). Quizás por esta razón el aislamiento del yo resulte frívolo e inútil; es decir, al definir al yo como relación, el poema hace de la alienación una imposibilidad. Como substancia fluctuante el yo nunca encontrará el centro que busca en la alienación. Es por ello que "lo irreductible" (la piedra filosofal, los mitos) sólo puede seducir "un instante". En términos de historia, "loirreductible" sedujo de hecho "un instante". Ello parece además alusión y crítica al pasado romántico, que idealizaba justamente la imposibilidad de relación, la alienación, los mitos. A la aridez del codiciado distanciamiento pasado, se opone la fluidez (fluidez, y fecundidad, pues los vocablos se generan uno a otro como veremos en el próximo apartado) del ahora de la escritura, evidenciada además por la cadena metonímica de significantes y significados, intercambio de fonemas y sememas. El cambio entonces se está haciendo ( $y$ haciendo al yo) siempre en el presente, y por ello no se puede fijar.

El poema tampoco privilegia un estado previo al distanciamiento; no opta por volver al tipo de relación de la que intentó huir, pues los juegos de palabras -el "calambur" - ridiculizan también los "parentescos", la "sociabilidad", "las sociedades de beneficiencia". A través de la aparente libre asociación que opera en el poema se critican las instituciones sociales: los parentescos no se presentan como expresión espontánea del sujeto social, pues se asocian con la religión, es decir, institución ("Mi repulsión hacia los parentescos me hizo eludir los padrinazgos, los padrenuestros"); las "sociedades de beneficiencia" cobran un nuevo sentido al estar yuxtapuestas a la "franela" (la caricia prostituida) y a los "ejercicios respiratorios", metáforas cómicas del acto sexual. En todo caso, la necesidad de confesar su fracaso a través de la escritura podría verse como un cambio, una nueva manera de relacionarse.

Tal vez la única alternativa capaz de liberar al sujeto de las relaciones pasadas sea justamente su constante cuestionamiento. Esto al mismo tiempo desplaza al yo de su centro. Lo despoja de lo "irreductible", lo torna ente cambiante. La contradicción, a través de la cual Girondo elude la estasis, afecta también al lector. Al buscarle el sentido al poema y sus partes, el lector tropieza con varios impases que impiden fijar un significado preciso y único. Se encuentra un buen ejemplo de esto en las frases: "Preferí el sublimado a lo sublime. Lo edificante a lo edificado". En primer lugar, si leemos "sublimado" comoadjetivo sustantivado (derivación poco poética) comoefecto de la sublimación en un objeto, es difícil percibir la diferencia que la estructura de la enunciación 
establece: lo sublimado puede ser también sublime. El paralelismo de las frases, en vez de aclarar la situación, la complica. Pero el sublimado es también una sustancia química ${ }^{7}$, un cuerpo volatilizado y condensado, que ha pasado por una transformación del estado sólido al vapor sin pasar por el estado líquido y la transformación inversa. En este caso el yo afirmaría que optó por algo concreto y material y que negó lo espiritual. Afirmaría también que optó por la destrucción física (los sublimados suelen ser corrosivos) y rechazó la "construcción" espiritual. Pero en la segunda frase citada, el primer término, que según su posición tendría que tener el mismo valor semántico que "sublimado", se refiere, al contrario, a lo espiritual, y en cambio es el segundo término - edificadon-el que pertenece a lo material. En nuestra búsqueda de un significado, de una lógica, nos vemos obligados por el texto a leer los vocablos de otra manera y recuperar el "calembour". En otras palabras, debemos hurgar en las posibilidades - tanto semánticas como morfológicas de la palabra. Morfológicas porque para que "edificante" se relacione lógicamente con "sublimado", hay que literalizar el vocablo, y hasta tansformarlo, a manera de operación química, en sustantivo. De cualquier manera siempre nos enfrentamos con la inevitabilidad de relacionar los elementos. El poema cumple con el proyecto vanguardista de convertir la obra de arte en puro cambio, en obraproceso, lo que a su vez impone una lectura también incompleta. La aliteración, la elección de fonemas que se aproximan como en el trabalenguas, no sólo aportan al ludismo del trayecto del lector, sino que también señalan que el cambio habita en la relación de los elementos materiales de la palabra. La repetición de palabras que comparten el mismo prefijo ("conjuré las conjuraciones más concomitantes con las conjugaciones conyugales") hace resaltar la naturaleza de la palabra como objeto "compuesto" de sonidos y silabas materiales que se prestan a la manipulación. Su origen es paradójicamente el cambio.

\section{ESTRUCTURA DEL CAMBIO}

Para Eugenio Coseriu, la asimilación (y confusión) fonética de los vocablos es una de las estrategias del cambio, especialmente en lo que el lingüista llama los "puntos débiles" del sistema ${ }^{8}$. Las consonantes líquidas $\Lambda / \mathrm{y} / \mathrm{r} /$ son ejemplo

\footnotetext{
${ }^{7}$ La elección de vocablos que provienen de la química es una constante en Girondo que se generaliza en los textos de En la masmédula. Allí incluso Girondo utiliza los símbolos de la química como material poético.

${ }^{8}$ Un "punto débil" es, según Coseriu, una circunstancia en la que se da una confusión y los usuarios eligen formas más simples e uniformes según sus necesidades. El ejemplo que da Coseriu es la sustitución del futuro sintético por formas perifrásticas: "El futuro ya era deficiente, desde el punto de vista de la expresividad, en el mismo latín clásico; y resultaba también algo extraño desde el punto de vista sistemático, por formarse de dos maneras enteramente distintas en las cuatro conjugaciones y por la coincidencia con el subjuntivo presente en la primera persona de las conjugaciones $3^{\frac{a}{a}}$ y $4^{\mathrm{a}}$. Constituía, por lo tanto, un "punto débil" del sistema". Pero la mutación se dio gracias a otra confusión:
} 
de esto. En el poema Girondo explota este "punto débil" al confundir los dos fonemas. Por ejemplo, en la primera frase parece estar conjurando el mecanismo del proceso del cambio: carambolas anticipa (por la confusión implícita en el sistema fónico), el vocablo que le sigue: calambur, y de hecho lo contiene. La inversión de fonemas está codificada en la lengua. Será quizá para explotar la fonetización que Girondo eligió evitar la escritura española normal de la palabra: "calembour", haciendo la inversión más obvia. Al mismo tiempo al reproducir la pronunciación francesa muestra comoel cambio se sitúaen el habla, dándole así una significación histórica y funcional. Pero tal vez lo más importante es que calambur queda intacto en su doble función: relacionado intimamente (en lo fonético) con carambolas y a la vez como vocablo semánticamente autónomo. Se expresa aquí, a través de las elecciones poéticas de Girondo, el concepto de cambio de L. Meyer, quien lo concibe no ya como sustitución-reemplazo, sino como alteración.

En las primeras palabras del poema, Girondo establece no sólo un concepto de la dinámica del cambio, sino que a su vez establece la norma estructural que irá variando a través del texto. Esta norma se puede articular, otra vez, en términos de una oposición entre relación y distanciamiento que hace eco a la temática del poema.

La norma frástica se puede esquematizar de la siguiente manera: Primer párrafo: verbo en $1^{a}$ posición, $1^{a}$ persona del singular, pretérito indefinido, circunstancia de fin/causa:

\begin{tabular}{|c|c|c|c|c|}
\hline sujeto tácito & verbo & objeto directo & preposición & término \\
\hline (yo) & abandoné & las carambolas & por & el calambur \\
\hline & & los madriaales & por & los mamboretás \\
\hline & & los entreveros & por & los entretelones \\
\hline & & los invertidos & por & los invertebrados \\
\hline " & dejé & $\begin{array}{c}\text { la sociabilidad } \\
\text { de } \\
\text { de } \\
\text { de }\end{array}$ & $\begin{array}{l}\text { a causa de } \\
\text { los solistas } \\
\text { los sodomistas } \\
\text { los solitarios }\end{array}$ & los sociologos \\
\hline " & $\begin{array}{l}\text { no quise } \\
\text { Preferí }\end{array}$ & $\begin{array}{l}\text { saber nada } \\
\text { el sublimado } \\
\text { lo edificante }\end{array}$ & $\begin{array}{l}\text { con } \\
\mathbf{a} \\
\mathbf{a}\end{array}$ & $\begin{array}{l}\text { los prostáticos } \\
\text { lo sublime } \\
\text { lo edificado }\end{array}$ \\
\hline
\end{tabular}

Es en este lugar del poema ("Preferí lo edificante a lo edificado) donde Girondo introduce una variante: el sujeto no es ya el yo tácito ("Mi repulsión hacia los parentescos") y el yo deviene objeto indirecto de la frase: "me hizo eludir", para

"... en el llamado "latín vulgar" se confunden a menudo $w$ y $b$, y con ello surge también la confusión de ciertas formas de futuro (amabit, amabimus) con las de perfecto de indicativo (amavit, amavimus)". Ver Coseriu, Sincronta, diacronta e historia 135-136. 
retornar en la siguiente ("conjuré las conjuraciones más concomitantes con las conjugaciones conyugales") según la norma establecida al comienzo. Esto, aparte de romper la monotonía, le da más posibilidades expresivas al poeta: con la progresión es más enfático el vaivén entre la acción volitiva del sujeto y la pasividad con que reacciona frente a los estímulos. Por otra parte, la variante aquí introducida logra que el segundo párrafo, con sus sujetos abstractos actuando sobre el yo, no sea abrupto, sino que esté ya anticipado.

La relación entre objeto directo y término(s) es estrecha, debido a la unión fonética. También se enfatiza la simetría, puesto que la primera frase establece que las relaciones serán pares:

\author{
carambolas/calambur \\ madrigales/mamboretás \\ entreveros/entretelones \\ invertidos/invertebrados
}

Este esquema será alterado definitivamente en el cuarto párrafo, pero antes se anticipa el cambio a través de una ruptura que permite la alteración. En la quinta línea del primer párrafo se encuentra la palabra "prostáticos", sin complemento paradigmático. Igual es el caso de la novena línea "Fui célibe con el mismo amor propio con que hubiese sido paraguas", frase con la que se establece además un "parentesco" entre vocablos sin relación fonética, que se repetirá luego con coronel/termómetro; ejercicios respiratorios/franela; recato/ bacalao.

El segundo párrafo es el más directo de todos. Aunque no abandona el juego de aliteración por completo, resulta quizás más prosaico, porque aquí Girondo trata el abandono -cambio- de una era conceptual. Se refiere a la estasis ("lo irreductible", "la mineralogía", la "piedra", los "minotauros", los "mitos"), y también al final del logos: Habla de un último intento inútil de recuperar el centro ("¿por qué razón los mitos no repoblarían ...). Como se anticipara arriba, existe una fuerte tensión entre simetría y asimetría. El párrafo evidencia simetría en cuanto empieza y termina con conceptos relacionados (irreductible/ piedra). También en cuanto reitera el juego de paralelismos fonéticos que siguen el patrón establecido en el primer párrafo del poema: mineralogía/ minotauros; felicidad/fecundidad/filosofía/fortuna. Usa asimismo paralelismos semánticos: mineralogía/piedra; minotauro/mito. Sin embargo, la simetría es minada porque, como se recordará, se trata de una piedra y de lo irreductible, y es la falsa simetría lo que sirve justamente de marco semántico al párrafo. La pluralidad y multiplicidad son entonces un engaño; de ahí que "nuestras circunvoluciones" sean "áridas"; giramos (o girábamos, se trata después de todo de un cambio rechazado por defectuoso) interminablemente alrededor del mismo centro. La seducción del logos lleva además al absurdo ("Mi ineptitud llegó a confundir a un coronel con un termómetro”). 
La ruptura del paralelismo se hace obvia en el cuarto párrafo. El cambio se consuma al predominar los grupos impares de tres vocablos, a veces fonéticamente relacionados, otras veces no:

$\begin{array}{ll}\text { Renuncié } & \begin{array}{l}\text { a las sociedades de } \\ \text { a los ejercicios respi } \\ \text { a la franela }\end{array} \\ \text { Fui } & \begin{array}{l}\text { metodista } \\ \text { malabarista } \\ \text { monogamista }\end{array} \\ & \text { las contradicciones } \\ \text { las contrariedades } \\ \text { los contrasentidos }\end{array}$

El predominio no es excluyente de los pares. El cambio se propone entonces como asimilación, alteración y concomitancia, y no como sustitución de lo dado. El absurdo, el sinsentido, se presenta no como sustituto de la significación, sino como su complemento. El juego de palabras - el calembour- no es gratuito (aunque el poema no propone preferencia por ningún significado). Por ejemplo, "gatismo" -que como nuevo vocablo opera un cambio-explota las posibilidades semánticas que la lengua ofrece a través de sufijos, entidades mínimas; en este caso se vale de "ismo", que significa sistema. Reconocida así la formación de esta palabra queda encontrarle el significado al vocablo compuesto. El artículo definido señala que se trata de algo supuestamente consabido ("un" gatismo tendría ya otras connotaciones). El verbo "cai" hace resaltar una de las características más sobresalientes de los gatos y es que siempre caen de pie. Esto sugiere un doble sentido: una derrota (caer) y un triunfo (caer de pie). Lo mismo sucede con "violencia de gatillo". Si pensamos en "gatillo" como disparador de un arma, "caer en el gatismo" tiene una connotación negativa, sería caer en lainactividad, la muerte; y haría además alusiones a otros aspectos oscuros de ese felino, tal como la mala suerte. En este caso se trataría de una estasis. Pero, la creación del vocablo gat-ismo, su composición en raíz y sufijo, se extiende y afecta a "gatillo", y hace de esta palabra existente una nueva composición, gat-illo, haciendo así uso del sufijo -illo, diminutivo que significa pequeñez; como una alternativa (según el mismo sistema) de gatito. En este caso, nos enfrentaríamos con una idea completamente contraria a la de arriba, pues al referirse a un "gatito" el poema terminaria afirmandola vital perpetuidad del gato (siempre tiene otra vida tras de cada muerte-caída). Hay que reconocer que en el primer caso la estasis se inscribe dentro de un marco mayor - la muerte-, más abarcador que el de la dinámica vital; en el segundo, se alberga dentro de la figura de un ente pequeño, insignificante si se quiere. No se encuentra, sin embargo, opción por ninguna de las dos posibilidades. El 
significado reside en todo caso en el cambio: juego, movimiento, entre las posibilidades, quizás en la imposibilidad de elegir un significado único.

No hay que malentender el énfasis que se da al significante en Espantapájaros, y en este poema en particular. No se anula el significado. Al contrario, el juego de aliteración y paralelismos convoca una mayor significación. Girondo hace suyo el mecanismo de la lengua como sistema de cambio y explota, literalmente, las posibilidades de la sustancia del signo. El tema del cambio se va desconstruyendo, como se ha visto, pero en cuanto esa desconstrucción opera dentro de un cambio sistematizado, la nota final es de afirmación del significado a través del sinsentido.

\section{LA TRANSFORMACION MATERIAL}

En el poema " 16 " se da otra versión del cambio: el cambio marcado por la relación del yo con el mundo material, biológico. Girondo bucea en la temática del cuerpo como expresión de la materia concreta la vez que establece la interdependencia entre lo corpóreo y lo epistemológico, y otra vez, como se vio en el poema " 4 ", se trata de una nueva noción.

Empieza el poema: "A unos les gusta el alpinismo. A otros les entretiene el dominó. A mí me encanta la transmigración" (OC 187). Plantear el cambio como placer alternativo es establecerlo dentro de la norma, y no como excepción o irregularidad, pues es una actividad ritual. Se reitera aquí la tensión entre lo estable y lo fluido, pero el poema añade otro elemento a la preocupación de Girondo por el cambio al proponerlo como quehacer físico. La transmigración se da entre cuerpos contemporáneos: "Yo me la paso transmigrando de un cuerpo a otro" (OC 187). Y el "cuerpo" se evoca en su sentido biológico, no espiritual:

\footnotetext{
Desde el amanecer, me instalo en algún eucalipto a respirar la brisa de la mañana.

¡Qué voluptuosidad la de ser tierra, la de sentirse penetrado de tubérculos, de rafces, de una vida latente que nos fecunda ... (OC 187).
}

Inscribir el cambio en el placer es darle cabida al deseo, escamotear la razón y la autoridad". A diferencia de la "Carta abierta a $L a P$ Púa", en la que Girondo afirma que "lo único realmente interesante es el mecanismo de sentir y pensar. ¡Prueba de existencia!" (OC 51). Aquí, en el poema " 16 ", el yo poético se manifiesta contra el peso de la razón:

9 Presentar lo lúdico como un intento de evadir la razón ya había encontrado su expresión
en Membretes: "Trasladar al plano de la creación la fervorosa voluptuosidad con que,
durante nuestra infancia, rompimos a pedradas todos los faroles del vecindario" (OC 146). 
Cuando la vida es demasiado humana júnicamente humana! _el mecanismo de pensar ¿no resulta una enfermedad más larga y más aburrida que cualquier otra? (OC 188).

Lolúdico confluye en el poema con lo corporal: "una vida latente que nos fecunda ... y nos hace cosquillas" (OC 187).

Parte del ludismo, y del ambiente natural, es el azar, explotado en general por las vanguardias. El "objet trouvé" ${ }^{10}$ es imagen y concepto central en cuanto niega la estasis de las formulaciones mecanicistas/orgánicas de la realidad y del arte. En el ámbito del arte, de la obra en particular, este concepto intenta desplazar al autor de su posición central; lo priva de su rol de creador. Girondo mina el concepto de "proyecto" como seguridad, al presentarnos un yo errático, que se deja mover por el azar: "Duermo una siesta mineral, dentro de la primera piedra que hallo en mi camino" (OC 186, énfasis nuestro). Traspasar los límites del yo (poético, autorial, epistemológico) es una de las metas que motivan la producción vanguardista. De ahí las producciones colectivas, los happenings recepciones colectivas del "arte", las "recetas" para escribir poemas". Y hecha juego, la poesía borra las lindes entre "arte" y praxis, e igualmente entre productor y destinatario, de esta manera haciendo de la poesía una actividad expansiva. Mientras que Breton temía que la poesía practicada de esta manera pudiese llevar al solipsismo, y de hecho buscara estrategias para evitarlo, en realidad practicar la poesia en lo cotidiano, para librarse de la estasis cultural, y no para producir "Arte" con mayúscula, sólo puede llevar al cuestionamiento del yo y del arte. Pero Girondo no es tan ingenuo como para creer que se trata de algo más que una experiencia, de un movimiento hacia algo que, por otra parte, nunca se encuentra. No espera borrar al yo, sino ponerlo a prueba constantemente. Usa los poderes cerebrales para socavar sus mismos mecanismos:

Antes de anochecer ya estoy pensando con un espíritu de gato (OC 87).

¡Pensar que durante toda su existencia la mayoria de los hombres no han sido ni siquiera mujer! ... ¿Cómo es posible que no se aburran de sus apetitos, de sus espasmos? (OC 188).

Hay conciencia de que aún lo supuestamente más auténtico del ser humano, como lo son los apetitos y espasmos, hasta el sexo, se han tornado convenciones de las que hay que liberarse. "Aunque me he puesto, muchas veces, un cerebro de imbécil, jamás he comprendido que se pueda vivir, eternamente, con un mismo esqueleto, un mismo sexo" (OC 188). La "aptitud de evasión" de la que habla no queda en el mero juego -o quizás no quepa aquí la dicotomía juego/

${ }^{10}$ Ver Peter Bürger, Theory of the Avant-Garde 57.

${ }^{11}$ P. Bürger, Theory of the Avant-Garde 53. 
seriedad-, no sólo no logra evadirse por completo, sino que al evadirse se encuentra:

[la aptitud de evasion] me permite trasladarme adonde yo no estoy: ser hormiga, jirafa, poner un huevo, y lo que es más importante aún, encontrarme conmigo mismo en el momento en que me había olvidado, casi completamente, de mi propia existencia (OC 88).

El mundo natural se le presenta al yo como diferencia, y paradójicamente (como en uno de los Membretes: "Sólo después de arrojarlo todo por la borda somos capaces de ascender a nuestra propia nada" $O C$ 149), el yo se afirma en la nada. Ahora se ve que el movimiento hacia lo otro, el cambio, no es una sustitución del yo por lo otro; lo que se afirma a través del poema es la ausencia: lo que el yo no es. Nuevamente Girondo afirma a través de la negación. Esta ausencia resulta en un acto poético vital, pues el cambio material opera gracias a una retórica; el yo transmigra gracias a un tropo: "Me gusta rumiar la pampa y el crepúsculo personificado en una vaca ... para cantarle con una voz de sapo ..." (OC 188, énfasis nuestro).

La metamorfosis poética se da también en el poema "14", donde Girondo hace hablar a "su abuela" repitiendo las palabras de $\mathrm{Membretes}^{12}$ : "la vida nos teje diariamente, una telaraña en las pupilas". Siendo el lenguaje el que sufre la estasis, hay que explotarlo como hace Girondo: "Poco a poco nos aprisiona la sintaxis, el diccionario ...” (OC 184). En el nombrar está quizá la salvación: “y aunque los mosquitos vuelen tocando la corneta, carecemos del coraje de llamarlos arcángeles" (OC 184, el énfasis es nuestro). Y es también lo "inútil" (los restos, los errores en el lenguaje) lo que posee la energía liberadora:

EI dolor de muelas, las estadísticas municipales, la utilización del aserrín, de la viruta y otros desperdicios, pueden proporcionarnos una satisfacción insospechada. Abre los brazos y no te niegues al clarinete, ni a las faltas de ortografia (OC 184, énfasis nuestro).

En lo que atañe al lenguaje, lo que en un momento dado se considera "error" (como las faltas de ortografia, las palabras mal usadas y vulgares), puede convertirse en norma, y parte del sistema lingüístico. Es así que las variantes en el habla (no importa su origen "inculto") dan testimonio de la libertad que los usuarios ejercen al "romper" reglas como quiere Coseriu"

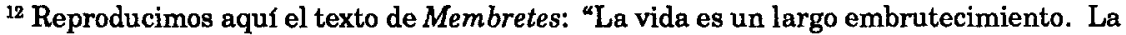
costumbre nos teje, diariamente, un telaraña en las pupilas; poco a poco nos aprisiona la sintaxis, el diccionario; los mosquitos pueden volar tocando la corneta, carecemos del coraje de llamarlos arcángeles, y cuando deseamos viajar nos dirigimos a una agencia de vapores en vez de metamorfosear una silla en un transatlántico" (OC 147).

${ }^{13}$ Dice Coseriu: "En efecto, los cambios se manifiestan en la sincronía, desde el punto de vista cultural, en las formas "esporádicas", en los llamados "errores corrientes" con respecto a la norma establecida y en los modos heterosistemáticos, comprobables en un hablar", Sincronta, diacronta e historia 117.
} 
El cambio en la obra de Girondo se sitúa cada vez más dentro de lo material, según lo evidencian los poemas de Persuasión de los días (1942): "Comunión plenaria" y "Arborescencia".

Extenderse más allá del yo en "Comunión plenaria" también quiere decir literalizar la expansión:

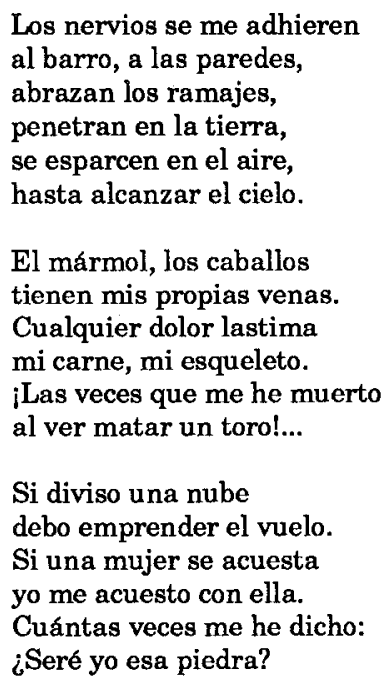

Nunca sigo un cadáver

sin quedarme a su lado.

Cuando ponen un huevo, yo también cacareo.

Basta que alguien me piense

para ser un recuerdo (OC 288-289).

Mientras que en Espantapájaros el yo persigue el cambio, aquí en este poema de Persuasión, la inevitabilidad de la metamorfosis señala la completa aceptación y asimilación del cambio de parte del yo (el uso de los pronombres "se me" demuestran que se trata de un acontecer externo a la voluntad). Sigue operando en la discusión del cambio la dinámica del yo y su ambiente. Aunque los verbos aluden a "comunión", a superación de la diferencia y espacio ("adhieren", “abrazan", "penetran") no se logra la "comunión plenaria" total que anuncia el título, pues esos mismos vocablos también implican la existencia de dos entidades: algo (los nervios) se adhiere a materiales y objetos diversos. Aunque se desplazan, los nervios no van perdiendo su cualidad; no dejan de serlo para convertirse en paredes, en barro, etc. Igual ocurre en la segunda estrofa. El mármol, los caballos y el yo lírico comulgan a través de la imagen de las venas. 
Sin embargo, las "venas" de los tres no tienen la misma significación, no brindan la misma información. En el caso del mármol, las venas son una imagen gráfica (se ven); en cuanto al caballo, las venas aluden a la vitalidad del animal; y el yo está situado entre (o más allá de) lo geológico y lo animal, sus "venas" entonces pertenecen a ambos dominios. El yo sería así una tercera categoría. La semejanza - las venas-es también el elemento que diferencia.

Esto es más explícito en la tercera estrofa, en la alusión a la mujer. El juego de palabras evoca el encuentro erótico (ya anticipado, por otra parte, en la primera estrofa con los verbos "abrazan", "penetran"), pero la "comunión" entre dos entes (mujer, yo) a través del acto de acostarse no resulta en la anulación de ninguno de los dos, más bien se da el acto erótico en términos de solidaridad, como en el poema " 23 " de Espantapájaros ${ }^{14}$. Los dos significados del significante "acostarse" han de quedar en pie, o se perdería el juego de palabras. Este juego de semejanza y diferencia ilumina a la vez la importante imagen de la "piedra" en la obra de Girondo. Al preguntarse "¿seré yo esa piedra?" afirma semejanza y diferencia a la vez. Es una pregunta retórica (no dice Cuántas veces me he preguntado, sino "Cuántas veces me he dicho"), lo que implica ya la respuesta negativa. De esta manera, la "pregunta" afirma la distancia, la diferencia entre el yo y la piedra en el mismo acto de cuestionar esa misma diferencia.

"Arborescencia”, también de $P D$, cuenta otro tipo de metamorfosis a través de una lírica narrativa que conserva la oralidad que opera desde los primeros textos de Girondo:

Creí que fuese un pelo rebelde, atormentado, pero al mirarme el pecho comprobé que era verde.

Pasaron noches y dias.

Apareció una hojita y despues otra ... y otra ... y todavía otra.

¿Un trébol de cuatro hojas?

¡Qué alegre!

¡Qué alegria!

Pero al morir los meses, una dura corteza recubría su tronco, mientras le iban creciendo unas cuantas ramitas.

\footnotetext{
${ }^{14}$ En este poema encontramos: “ ¿Una colonia de microbios se aloja en los pulmones de una señorita? Solidario de los microbios, de los pulmones y de la señorita. ¿A un estudiante se le ocurre esperar el tranvía adentro del ropero de una mujer casada? Solidario del ropero, de la mujer casada, del tranvía, del estudiante y de la espera" (OC 200).
} 


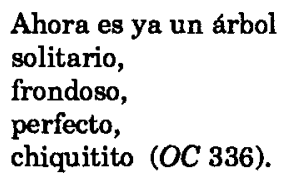

Al manifestarse como un pelo "rebelde", lo otro - la diferencia- aparece primero como un cambio normal en el cuerpo del yo. Lo normal para el yo lírico es que se trate de un pelo "rebelde", con lo que Girondo hace del cambio una norma de la naturaleza. Y, como norma natural, el cambio se hace perpetuamente; así no responde al concepto de sustitución, sino de alteración.

Desde el principio del poema se establece la con-vivencia del yo y el otro en su cuerpo. El yo no se confunde con el árbol y, sin llegar a ser tótem, tiene una relación más estrecha de laque tendría con una "representación" o identificación, pues el árbol no se presenta como antepasado, sino como coetáneo. Ambos comparten un tiempo y un espacio (literalmente). Girondo merma el peso simbólico del árbol a través de los diminutivos ("hojita","ramitas", "chiquitito") y también al brindarle a ambos su propio espacio. Aunque termina de crecer al final del poema, el árbol está contenido: es "solitario", "perfecto", y sobre todo, "chiquitito". No se apodera del yo ni de su cuerpo. Así logra un acto múltiple: le da más cabida a lo concreto al quitarle peso e importancia, y empequeñeciendo al yo, le da más vida. Esto se logra también haciendo coincidir imágenes supuestamente "contrarias": el árbol tiene una "dura corteza" al mismo tiempo que "ramitas", diminutivo que merma el primer término. Al evocar el modelo natural, el texto de Girondo hace de la escritura un acto igualmente móvil y cambiante, en el que la palabra cobra mayor significación por rebajarse a su materia.

El cambio en la obra de Girondo se muestra una y otra vez como norma y no excepción, cotidiana manifestación de la libertad (con minúscula) del sujeto enunciador y, como tal se opone a la noción ideal de una completa transformación. Al topar con el origen estrepitoso de la palabra, Girondo convierte el hacerse mismo del lenguaje en metáfora del contenido de su propia poesía. Amalgama de objetos sonoros sin-sentido, conjunto de relaciones materiales, cuyo significado surge de la manipulación arbitraria de sus elementos, la palabra parece anticipar la labor del poeta y el ciudadano. Sin fundirse con lo otro y perder su diferencia, el yo, igual que los mismos componentes de la palabra, se define como relación cambiante. La mirada del yo pierde la perspectiva privilegiada del centro, pues su afán de armar significados - de relacionar-, resulta de su voluntad al principio, pero en los poemas posteriores es un acontecer codificado en el sistema mismo del lenguaje; como se halla codificada también la imposibilidad de fijar significados. Con ello, el yo deviene autor de su propia ejecución en su doble sentido. Se da vida y se da muerte. De ahí, se trata de una muerte necesaria y vital ("Dadle muerte a esos muertos", dirá enérgicamente en Campo nuestro, donde forja una fresca identidad latinoamericana). Sumarse a la dinámica del cambio implica una muerte re-generadora. 